\title{
A new macrocycle that forms pseudorotaxane-like complexes with dibenzylammonium ions
}

\author{
Pin-Nan Cheng, Wei-Chung Hung and Sheng-Hsien Chiu* \\ Department of Chemistry, National Taiwan University, No. 1, Sec. 4, Roosevelt Road, Taipei 10617, Taiwan, ROC
}

Received 24 February 2005; revised 8 April 2005; accepted 11 April 2005

Available online 29 April 2005

\begin{abstract}
A new host molecule in which only one diethylene glycol chain (i.e., a loop possessing only three oxygen atoms) suitably positioned in a macroring recognizes a $\mathrm{DBA}^{+}$ion to form a 1:1 pseudorotaxane-like complex. To confirm unambiguously that the pseudorotaxane exists in solution, a corresponding interlocked rotaxane molecule was synthesized.
\end{abstract}

(C) 2005 Elsevier Ltd. All rights reserved.

Although many elegant molecular switches ${ }^{1}$ and actuators $^{2}$ based on interlocked molecular compounds and threaded supramolecular complexes have been developed in the past two decades, the number of recognition motifs that can be exploited for the preparation of these systems remains limited. Among these few recognition systems, the crown ether/dibenzylammonium ion $\left(\mathrm{DBA}^{+}\right)$pair $^{3}$ is one of the most accessible systems for the construction of functional (supra)molecular entities, in which the nature of the complexation is very sensitive
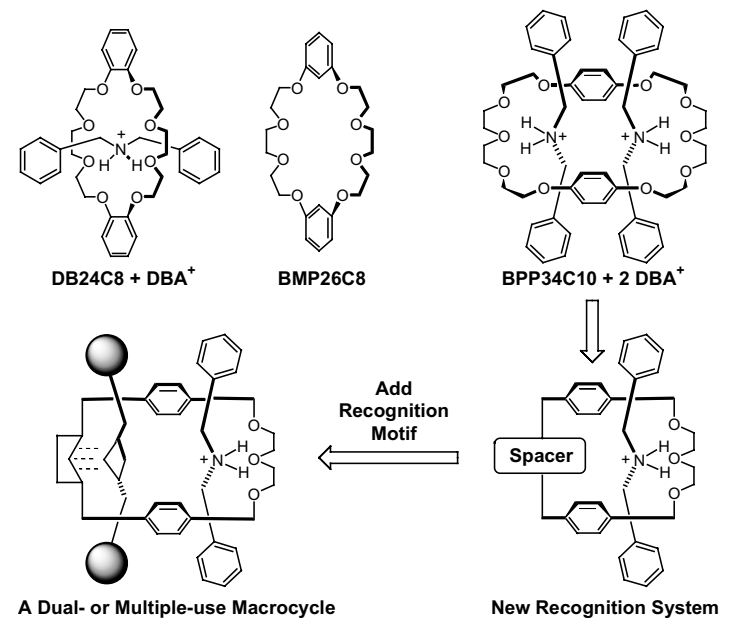

Figure 1.

\footnotetext{
Keywords: Crown ether; Dibenzyl ammonium ion; Pseudorotaxane.

* Corresponding author. Tel.: +886 2 23690152x150; fax: +886 2

24980963; e-mail: shchiu@ntu.edu.tw
}

to the size and constitution of the crown ether. For example, $\mathrm{DBA}^{+}$ions form high-affinity pseudorotaxane-like ${ }^{4}$ complexes with dibenzo[24]crown-8 (DB24C8) in relatively nonpolar solvents ${ }^{5}$ (Fig. 1), but the slightly larger structural isomer of this crown ether, bis- $m$-phenylene[26]crown-8 (BMP26C8), displays a negligible binding affinity toward the $\mathrm{DBA}^{+}$ion. $^{6}$ In contrast, the significantly larger crown ether, bis- $p$-phenylene[34]crown-10 (BPP34C10), is capable of complexing two $\mathrm{DBA}^{+}$ions simultaneously and relatively strongly in nonpolar solvents. ${ }^{7}$

In the latter 1:2 (host:guest) complex, both in solution and in the solid state, each $\mathrm{DBA}^{+}$ion binds to one of the tetraethylene glycol units of BPP34C10. This arrangement prompts an interesting question: would only one properly placed oligoethylene glycol chain in a macroring be sufficient to form 1:1 pseudorotaxanelike complexes with $\mathrm{DBA}^{+}{ }^{\text {ions? }}{ }^{8}$ If the answer is 'yes,' then the chemical skeletons of the macrocyclic oligoethers, which generally consist of two oligoethylene glycol chains for synthetic simplicity, could become much more varied in structure. Furthermore, it may become possible to prepare hosts that can recognize two (or more) different classes of guest molecules by linking together into a macrocycle an oligoethylene glycol loop and another recognition motif (Fig. 1). Such double-recognition macrocycles would have potential applications in, for example, the fine tuning of complexes, the construction of supramolecular catalytic systems, or the preparation of sensitive molecular switches. In this letter, we report a new host molecule in which only one diethylene glycol chain (i.e., a loop possessing only three 
oxygen atoms) suitably positioned in a macroring recognizes a $\mathrm{DBA}^{+}$ion to form a relatively strong 1:1 pseudorotaxane-like complex. To confirm unambiguously that the pseudorotaxane exists in solution, we have synthesized a corresponding interlocked molecular version of this complex, namely a [2]rotaxane.

Based on CPK molecular models and molecular mechanics calculations, we believed that positioning both $p$-xylene and diethylene glycol linkers between the phenolic rings of macrocycle 1 would position these two phenol units at a suitable $\pi$-stacking distance for guest reception. Moreover, the three oxygen atoms in the diethylene glycol chain of macrocycle 1 seemed to be located appropriately to provide a good reception site for two $[\mathrm{N}-\mathrm{H} \cdots \mathrm{O}]$-type hydrogen bonds with a threaded $\mathrm{DBA}^{+}$ion. In addition, the $\pi$-electron-rich phenolic rings are positioned appropriately for potential $\mathrm{N}^{+} \mathrm{C}-\mathrm{H} \cdots \pi,{ }^{9} \quad \mathrm{~N}^{+}-\mathrm{H} \cdots \pi^{10}$ and/or cation $-\pi^{11}$ interactions with the guest's $\mathrm{CH}_{2} \mathrm{NH}_{2}{ }^{+} \mathrm{CH}_{2}$ center. We synthesized macrocycle 1 (Scheme 1) using a simple two-step approach: first reacting phenol 2 with $\alpha, \alpha^{\prime}$-dibromo- $p$ xylene 3 to afford diol $\mathbf{4}^{12}$ and then performing a [1+1] macrocyclization between $\mathbf{4}$ and ditosylate $\mathbf{5} .{ }^{13}$

The ${ }^{1} \mathrm{H}$ NMR spectrum (Fig. 2b) of an equimolar mixture of macrocycle 1 and DBA.PF ${ }_{6}$ in $\mathrm{CDCl}_{3} / \mathrm{CD}_{3} \mathrm{CN}$ (1:1) displays three sets of resonances: one set for free 1 (Fig. 2a), one for free DBA.PF 6 (Fig. 2c), and one for the 1:1 complex formed between macrocycle 1 and the $\mathrm{DBA}^{+}$ion. The presence of both free and complexed species in equilibrium implies that the rates of complexation and decomplexation are both slow on the ${ }^{1} \mathrm{H}$ NMR timescale at $400 \mathrm{MHz}$ and $298 \mathrm{~K} .{ }^{14}$ The splitting of the originally overlapping signals for the protons of the diethylene glycol unit's two methylene groups in macrocycle 1 into two separate multiplets - one shifted upfield to $\delta 3.06$ and the other downfield to $\delta 3.59$-in the presence of the salt suggests that hydrogen bonding probably takes place between the host and guest, but the most remarkable shift occurs for the methylene protons adjacent to the ammonium center. When uncomplexed, these protons resonate at ca. $4.17 \mathrm{ppm}$, but this signal experiences an upfield shift of $>2 \mathrm{ppm}$ (to $\delta 1.95$ ) upon complexation with 1 , which suggests that the $\mathrm{NH}_{2}{ }^{+}$center is positioned in the shielding zone between the two phenol units of $\mathbf{1}$, as would be expected when [N$\mathrm{H} \cdots \mathrm{O}]$ hydrogen bonds exist. ${ }^{15}$ Unfortunately, we were not able to detect the signal for the resonance of the $\mathrm{NH}_{2}{ }^{+}$protons, which we expect to also undergo a signif-

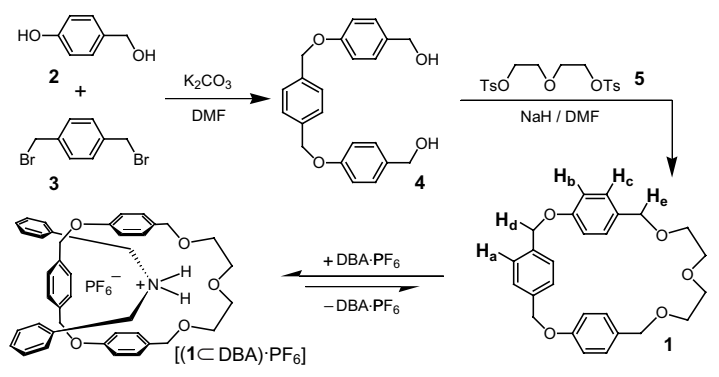

Scheme 1.

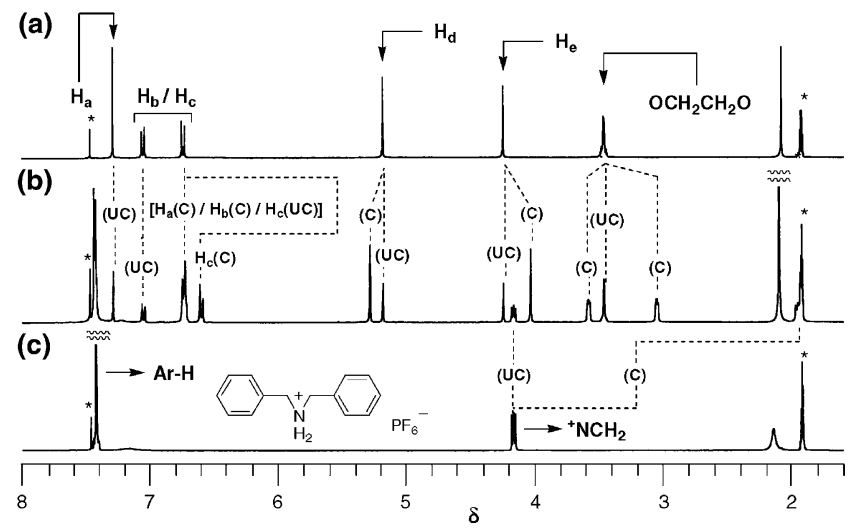

Figure 2. Partial ${ }^{1} \mathrm{H}$ NMR spectra $\left[400 \mathrm{MHz}, \mathrm{CDCl}_{3} / \mathrm{CD}_{3} \mathrm{CN}(1: 1)\right.$, $298 \mathrm{~K}$ ] of (a) macrocycle $\mathbf{1}$, (b) an equimolar mixture of $\mathbf{1}$ and $\mathrm{DBA} \cdot \mathrm{PF}_{6}(10 \mathrm{mM})$, and (c) $\mathrm{DBA} \cdot \mathrm{PF}_{6}$. The descriptors (c) and (uc) refer to complexed and uncomplexed states of the components.

icant upfield shift, possibly because of severe broadening. The resonances of the phenolic protons shift upfield to 6.60 and $6.74 \mathrm{ppm}$ from their original positions ( $\delta 6.74$ and 7.06 , respectively), which suggests the existence of possible aryl-aryl interactions caused by the threading of the $\mathrm{DBA}^{+}$ion into the cavity of macroring $\mathbf{1}$. Thus, these shifts suggest that the complexation between macrocycle $\mathbf{1}$ and the $\mathrm{DBA}^{+}$ion in solution is likely to have the geometry of a [2]pseudorotaxane. Using a single-point method, ${ }^{16}$ we determined the association constant $\left(K_{\mathrm{a}}\right)$ of this system to be $550 \mathrm{M}^{-1}$ in $\mathrm{CDCl}_{3} / \mathrm{CD}_{3} \mathrm{CN}(1: 1)$ and $15,000 \mathrm{M}^{-1}$ in $\mathrm{CD}_{3} \mathrm{NO}_{2}$; that is, the binding strength is comparable to those of crown ether-containing complexes. ${ }^{5-7,17}$

To prove unambiguously that a [2]pseudorotaxane complex forms between macrocycle 1 and the $\mathrm{DBA}^{+}$ion in solution, we chose to stopper such a complex to form a corresponding [2] rotaxane. From a CPK molecular model, it appeared that because compound $\mathbf{1}$ is a 25 membered-ring macrocycle that incorporates three rigid benzene rings, diethyl phosphoramidate groups ${ }^{18}$ would be suitable stoppers. Thus, we added triethyl phosphite $(200 \mathrm{mM})$ to a solution of benzylic azide $\mathbf{6}-\mathrm{H} \cdot \mathrm{PF}_{6}$ $(100 \mathrm{mM})$ and macrocycle $1(150 \mathrm{mM})$ in $\mathrm{CH}_{2} \mathrm{Cl}_{2}$ and isolated the corresponding [2] rotaxane $7-\mathrm{H} \cdot \mathrm{PF}_{6}$ in $57 \%$ yield after silica gel column chromatography (Scheme 2). ${ }^{19}$

The ${ }^{1} \mathrm{H}$ NMR spectrum (Fig. 3a) of the [2]rotaxane 7$\mathrm{H} \cdot \mathrm{PF}_{6}$ recorded in $\mathrm{CD}_{3} \mathrm{CN}$ displays an upfield shift in

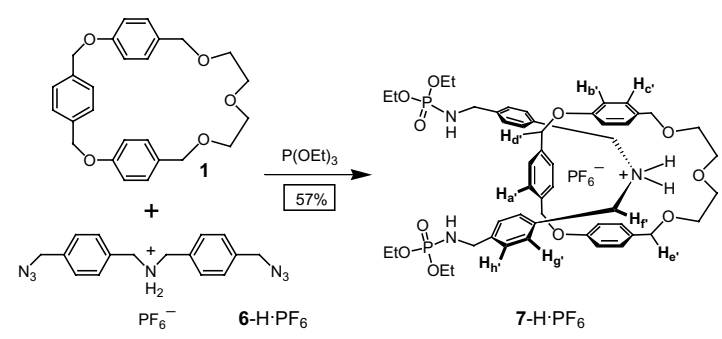

Scheme 2. 


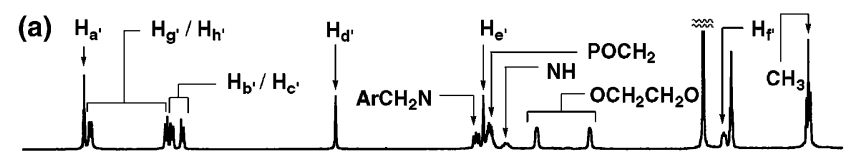

(b)

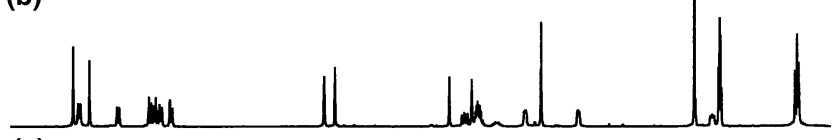

(c)

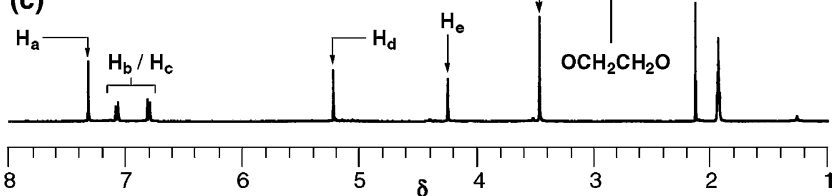

Figure 3. Partial ${ }^{1} \mathrm{H}$ NMR spectra $\left(400 \mathrm{MHz}, \mathrm{CD}_{3} \mathrm{CN}, 10 \mathrm{mM}\right.$, $298 \mathrm{~K}$ ) of (a) [2] rotaxane $7-\mathrm{H} \cdot \mathrm{PF}_{6}$, (b) an equimolar mixture of rotaxane $7-\mathrm{H} \cdot \mathrm{PF}_{6}$ and macrocycle $\mathbf{1}$, and (c) macrocycle $\mathbf{1}$.

the position of the signal of the resonance of the methylene protons adjacent to the ammonium center and those of the ethylene protons of the encircled macrocyclic component of $7-\mathrm{H} \cdot \mathrm{PF}_{6}$, relative to the positions of these signals in its free components, which confirms that the interactions between these components in the rotaxane are similar to those present in the initial complex. The ${ }^{1} \mathrm{H}$ NMR spectrum (Fig. 3b) of an equimolar mixture of $7-\mathrm{H} \cdot \mathrm{PF}_{6}$ and macrocycle 1 (10 $\mathrm{mM}$ each) in $\mathrm{CD}_{3} \mathrm{CN}$ at $298 \mathrm{~K}$ corresponds to a superimposition of the two spectra (Fig. 3a and c) of the separate components. These spectra establish that no exchange occurs between the macrocycle and dumbbell components in solution and, therefore, proves the constitutional integrity of the [2]rotaxane. ${ }^{20}$

The fact that it is possible to generate [2]pseudorotaxane complexes in solution from the interaction of $\mathrm{DBA}^{+}$ ions with a macrocycle 1 that contains just three oxygen atoms suggests that the cooperative effect of the five to eight oxygen atoms found in the recognition sites of most of the crown ethers that have been used previously to complex $\mathrm{DBA}^{+}$ions is not a necessary prerequisite for efficient binding. Indeed, it appears that $\mathrm{N}^{+} \mathrm{C}-$ $\mathrm{H} \cdots \pi, \mathrm{N}^{+}-\mathrm{H} \cdots \pi$ and/or cation $-\pi$ interactions can be induced to play extremely important roles in stabilizing such macrocycle-ammonium ion complexes. We are now investigating the complexation behavior of macrocycle 1 toward electron-deficient aromatic molecules in addition to constructing related macrocycles possessing double-recognition properties.

\section{Acknowledgements}

We thank the National Science Council (Taiwan) for financial support (NSC-93-2113-M-002-020).

\section{References and notes}

1. (a) Molecular Switches; Feringa, B. L., Ed.; VCH-Wiley: Weinheim, 2001; (b) Gatti, F. G.; León, S.; Wong, J. K. Y.; Bottari, G.; Allieri, A.; Morales, M. A. F.; Teat, S. J.; Frochet, C.; Leigh, D. A.; Brouwer, A. M.; Zerbetto, F.
Proc. Natl. Acad. Sci. U.S.A. 2003, 100, 10-14; (c) Badjic', J. D.; Balzani, V.; Credi, A.; Silvi, S.; Stoddart, J. F. Science 2004, 303, 1845-1849.

2. (a) Armaroli, N.; Balzani, V.; Collin, J.-P.; Gaviña, P.; Sauvage, J.-P.; Ventura, B. J. Am. Chem. Soc. 1999, 121, 4397-4408; (b) Balzani, V.; Credi, A.; Venturi, M. Molecular Machines and Devices; Wiley-VCH: Weinheim, 2003.

3. (a) Cantrill, S. J.; Pease, A. R.; Stoddart, J. F. J. Chem. Soc., Dalton Trans. 2000, 3715-3734; (b) Clifford, T.; Abushamleh, A.; Busch, D. H. Proc. Natl. Acad. Sci. U.S.A. 2002, 99, 4830-4836; (c) Gibson, H. W.; Yamaguchi, N.; Jones, J. W. J. Am. Chem. Soc. 2003, 125, 35223533 .

4. (a) Asakawa, M.; Ashton, P. R.; Balzani, V.; Boyd, S. E.; Credi, A.; Mattersteig, G.; Menzer, S.; Montalti, M.; Raymo, F. M.; Ruffilli, C.; Stoddart, J. F.; Venturi, M.; Williams, D. J. Eur. J. Org. Chem. 1999, 985-994; (b) Huang, F.; Zakharov, L. N.; Rheingold, A. L.; Jones, J. W.; Gibson, H. W. Chem. Commun. 2003, 2122-2123.

5. (a) Kolchinski, A. G.; Busch, D. H.; Alcock, N. W. J. Chem. Soc., Chem. Commun. 1995, 1289-1291; (b) Ashton, P. R.; Campbell, P. J.; Chrystal, E. J. T.; Glink, P. T.; Menzer, S.; Philp, D.; Spencer, N.; Stoddart, J. F.; Tasker, P. A.; Williams, D. J. Angew. Chem., Int. Ed. Engl. 1995, 34, 1865-1869.

6. (a) Bryant, W. S.; Guzei, I. A.; Rheingold, A. L.; Merola, J. S.; Gibson, H. W. J. Org. Chem. 1998, 63, 7634-7639; (b) Cantrill, S. J.; Fulton, D. A.; Heiss, A. M.; Pease, A. R.; Stoddart, J. F.; White, A. J. P.; Williams, D. J. Chem. Eur. J. 2000, 6, 2274-2287.

7. Ashton, P. R.; Campbell, P. J.; Chrystal, E. J. T.; Glink, P. T.; Menzer, S.; Philp, D.; Spencer, N.; Stoddart, J. F.; Tasker, P. A.; Williams, D. J. Angew. Chem., Int. Ed. Engl. 1995, 34, 1869-1871.

8. The even-larger crown ethers tris- $p$-phenylene[51]crown15 and tetrakis-p-phenylene[68]crown-20 form complexes with $\mathrm{DBA}^{+}$ions (three and four of them, respectively), which seems to suggest that a single tetraethylene glycol chain (i.e., a loop possessing five oxygen atoms) is all that is really required for generating pseudorotaxane-like complexes in solution and in the solid state. See: Ashton, P. R.; Fyfe, M. C. T.; Glink, P. T.; Menzer, S.; Stoddart, J.F.; White, A. J. P.; Williams, D. J. J. Am. Chem. Soc. 1997, 119, 12514-12524.

9. Nishio, M.; Umezawa, Y.; Hirota, M.; Takeuchi, Y. Tetrahedron 1995, 51, 8665-8701.

10. (a) Palit, S. R.; Mukherjee, S.; De, S. K. J. Phys. Chem. 1971, 75, 2404-2405; (b) Nikolic, A. D.; Kobilarov, N. L.; Brzic, A. N. J. Mol. Struct. 1983, 99, 179-188.

11. Ma, J. C.; Dougherty, D. A. Chem. Rev. 1997, 97, 13031324.

12. Typical procedure for the synthesis of diol $\mathbf{4}$ and its selected spectral data: A mixture of 4-hydroxybenzyl alcohol 2 (3.72 g, $30 \mathrm{mmol}), \alpha, \alpha^{\prime}$-dibromo- $p$-xylene $\mathbf{3}$ $(2.63 \mathrm{~g}, 10 \mathrm{mmol})$, and $\mathrm{K}_{2} \mathrm{CO}_{3}(10 \mathrm{~g}, 72.4 \mathrm{mmol})$ in $\operatorname{DMF}(50 \mathrm{ml})$ was heated at $50{ }^{\circ} \mathrm{C}$ for 2 days. The reaction mixture was cooled to room temperature and the organic solvent was evaporated under reduced pressure. The residue was washed with $\mathrm{CH}_{2} \mathrm{Cl}_{2}(500 \mathrm{ml}), \mathrm{H}_{2} \mathrm{O}(500 \mathrm{ml})$, and $\mathrm{MeOH}(150 \mathrm{ml})$ to afford the desired product 4 as a brown solid $(3.14 \mathrm{~g}, \quad 90 \%) .{ }^{1} \mathrm{H}$ NMR $(400 \mathrm{MHz}$, $\left.\mathrm{CD}_{3} \mathrm{SOCD}_{3}\right): \delta=4.40(\mathrm{~s}, 4 \mathrm{H}), 5.08(\mathrm{~s}, 4 \mathrm{H}), 6.94(\mathrm{~d}$, $J=8 \mathrm{~Hz}, 4 \mathrm{H}), 7.21(\mathrm{~d}, J=8 \mathrm{~Hz}, 4 \mathrm{H}), 7.43(\mathrm{~s}, 4 \mathrm{H}) .{ }^{13} \mathrm{C}$ NMR (100 MHz, $\left.\mathrm{CD}_{3} \mathrm{SOCD}_{3}\right): \delta=62.4,68.7,113.9$, 127.0, 127.3, 134.1, 136.0, 156.2. MS (FAB): $\mathrm{m} / \mathrm{z} 389.1$ for $[\mathrm{M}+\mathrm{K}]^{+}$.

13. Typical procedure for the synthesis of macrocycle $\mathbf{1}$ and its selected spectral data: Diethylene glycol ditosylate 5 
$(5.95 \mathrm{~g}, 14.4 \mathrm{mmol})$ was added slowly to a solution of diol $4(5.0 \mathrm{~g}, 14.4 \mathrm{mmol})$ and $\mathrm{NaH}(1.75 \mathrm{~g}, 42.8 \mathrm{mmol})$ in DMF $(700 \mathrm{ml})$ and the resulting mixture was stirred at room temperature for 7 days. The reaction was quenched by the addition of $\mathrm{MeOH}(10 \mathrm{ml})$ and then the organic solvent was evaporated under reduced pressure. The residue was partitioned between $\mathrm{H}_{2} \mathrm{O}(500 \mathrm{ml})$ and $\mathrm{CH}_{2} \mathrm{Cl}_{2}(500 \mathrm{ml})$; the organic layer was collected, dried $\left(\mathrm{MgSO}_{4}\right)$, and concentrated to afford a crude product, which was then purified by column chromatography $\left(\mathrm{SiO}_{2}\right.$; EtOAc/Hexanes, $3: 7)$ to give macrocycle $\mathbf{1}$ as a white solid $(183 \mathrm{mg}$, $3 \%) .{ }^{1} \mathrm{H}$ NMR $\left(400 \mathrm{MHz}, \mathrm{CDCl}_{3}\right): \delta=3.50(\mathrm{~m}, 4 \mathrm{H}), 3.60$ (m, 4H), 4.39 (s, 4H), 5.17 (s, 4H), 6.65 (d, $J=8 \mathrm{~Hz}, 4 \mathrm{H})$, $7.06(\mathrm{~d}, J=8 \mathrm{~Hz}, 4 \mathrm{H}), 7.27$ (s, 4H). ${ }^{13} \mathrm{C} \mathrm{NMR}(100 \mathrm{MHz}$, $\left.\mathrm{CDCl}_{3}\right): \delta=69.1,69.6,70.5,72.6,115.6,127.0,129.0$, 130.3, 136.8, 157.0. MS (FAB): $m / z 421.2$ for $[\mathrm{M}+\mathrm{H}]^{+}$.

14. Connors, K. A. Binding Constants; Wiley: New York, 1987.

15. Chiu, S.-H.; Pease, A. R.; Stoddart, J. F.; White, A. J. P.; Williams, D. J. Angew. Chem., Int. Ed. 2002, 41, 270274.

16. For a description of this single-point method, see: Ashton, P. R.; Chrystal, E. J. T.; Glink, P. T.; Menzer, S.; Schiavo, C.; Spencer, N.; Stoddart, J. F.; Tasker, P. A.; White, A. J. P.; Williams, D. J. Chem. Eur. J. 1996, 2, 709-728; Because of ion-pairing effects, the values of $K_{\mathrm{a}}$ determined this way are merely 'ballpark' figures; for a discussion of a method for determining the values more precisely, see: Jones, W. J.; Gibson, H. W. J. Am. Chem. Soc. 2003, 125, 7001-7004.
17. The binding constant for the interaction between DB24C8 and $\mathrm{DBA}^{+}$in $\mathrm{CH}_{3} \mathrm{NO}_{2}$ was determined to be $8000 \mathrm{M}^{-1}$, which is about half the value of the one between macrocycle 1 and DBA $^{+}$. See: Chiu, S.-H.; Liao, K.-S.; $\mathrm{Su}$, J.-K. Tetrahedron Lett. 2004, 45, 213-216.

18. Hung, W.-C.; Liao, K.-S.; Liu, Y.-H.; Peng, S.-M.; Chiu, S.-H. Org. Lett. 2004, 6, 4183-4186.

19. Typical procedure for the synthesis of [2] rotaxane $7-\mathrm{H} \cdot \mathrm{PF}_{6}$ and its selected spectral data: Triethyl phosphite $(0.05 \mathrm{ml}$, $0.28 \mathrm{mmol}$ ) was added slowly to a solution of $\mathbf{6}-\mathrm{H} \cdot \mathrm{PF}_{6}$ $(60 \mathrm{mg}, 0.14 \mathrm{mmol})$ and macrocycle $1(90 \mathrm{mg}, 0.22 \mathrm{mmol})$ in $\mathrm{CH}_{2} \mathrm{Cl}_{2}(1.4 \mathrm{ml})$. After the mixture had stirred at ambient temperature for $16 \mathrm{~h}$, the solvent was evaporated under reduced pressure. The residue was purified chromatographically $\left(\mathrm{SiO}_{2}: \mathrm{CH}_{2} \mathrm{Cl}_{2} / \mathrm{CH}_{3} \mathrm{OH}, 98: 2\right)$ and the desired [2] rotaxane $7-\mathrm{H} \cdot \mathrm{PF}_{6}$ was isolated as a white solid $(0.09 \mathrm{~g}, 57 \%) .{ }^{1} \mathrm{H}$ NMR $\left(400 \mathrm{MHz}, \mathrm{CD}_{3} \mathrm{CN}\right): \delta=1.42(\mathrm{t}$, $J=6.8 \mathrm{~Hz}, 12 \mathrm{H}), 2.14(\mathrm{t}, J=6.8 \mathrm{~Hz}, 4 \mathrm{H}), 3.26-3.29(\mathrm{~m}$, $4 \mathrm{H}), 3.72-3.74(\mathrm{~m}, 4 \mathrm{H}), 3.97-4.00(\mathrm{~m}, 2 \mathrm{H}), 4.09-4.17(\mathrm{~m}$, $8 \mathrm{H}), 4.19(\mathrm{~s}, 4 \mathrm{H}), 4.23-4.27(\mathrm{~m}, 4 \mathrm{H}), 5.44(\mathrm{~s}, 4 \mathrm{H}), 6.76(\mathrm{~d}$, $J=10.8 \mathrm{~Hz}, 4 \mathrm{H}), 6.84(\mathrm{~d}, J=7.6 \mathrm{~Hz}, 4 \mathrm{H}), 6.89$ (d, $J=10.8 \mathrm{~Hz}, 4 \mathrm{H}), 7.54(\mathrm{~d}, J=7.6 \mathrm{~Hz}, 4 \mathrm{H}), 7.59(\mathrm{~s}, 4 \mathrm{H})$. ${ }^{13} \mathrm{C}$ NMR $\left(100 \mathrm{MHz}, \mathrm{CH}_{3} \mathrm{CN}\right): \delta=17.8\left(J_{\mathrm{PC}}=6.9 \mathrm{~Hz}\right)$, $46.3,52.2,63.8\left(J_{\mathrm{PC}}=5.3 \mathrm{~Hz}\right), 69.1,70.8,72.1,75.2,117.3$, $128.7,128.8,129.6,129.7,130.5,132.4,138.6,142.9$ $\left(J_{\mathrm{PC}}=5.3 \mathrm{~Hz}\right), 158.6$; MS (FAB): $\mathrm{m} / z$ 948.4 for $[7-\mathrm{H}]^{+}$.

20. A similar method has been applied previously to confirm the integrity of [2]rotaxanes. See: Chiu, S.-H.; Stoddart, J. F. J. Am. Chem. Soc. 2002, 124, 4174-4175. 